\title{
SIMULATION AND MODELING IN CRISIS MANAGEMENT
}

\author{
Martin Ficek* \\ Tomas Bata University in Zlín, Czech Republic
}

This article deals with the possibilities of modeling and simulation in terms of crisis management. The first part deals with simulations and modeling in the form of realized trainings of Integrated Rescue System (IRS) and crisis management (CM). It is focused on the most important aspects of modeling and simulation in CM conditions. In the following part, we are evaluating the selected SW modeling and simulation from the point of view of their possibilities and suitability for relation to CM. Based on expert consultation; tasks are defined that the SW should manage. In the last part, using the knowledge from the previous parts, the possible development in the area of SW modeling and simulation in CM is identified.

Key words: Simulation model, Models, Simulations

\section{INTRODUCTION}

Modern time influences a wide area of disciplines and crisis management is not the exception. One of the areas where this trend can be seen as the issue is training and preparation for extraordinary events (EE) and crisis situations (CS) - primarily the Fire Rescue Service of the Czech Republic (FRS) and the Integrated Rescue System (IRS). This is evidenced by the number of planned IRS trainings, when 65 were planned for the first half of 2017. Therefore, this article deals with simulations and modeling of leakage of dangerous substances. This actual problem is proven by the fact that 5 trainings are primarily focused on this issue. With respect to the amount of trainings (floods, fires, active shooter, and highly contagious diseases, etc.) is not an insignificant number, even though, the leakage of dangerous substances (DS) is included in other trainings as secondary consequences.

For example in these trainings:

- February 7, 2017-7 units of FRS and fire protection units (FPO) participated in the training of EE, namely DS ammunition from the new training hall, which was held in Třinec. [1]

- June 29, 2017 - 6 units of FRS and FPO was training the EE with the leakage of dangerous substance (ammonia). This training was held in the premises of the MP Krásno in Ostrava-Martinov. [2]

- July 31, $2017-7$ units of FRS and FPO trained EE with DS (ammonia) which was leaking from multifunctional hall Polárka in Frýdek-Místek. [3]

- March 3, 2017 - the MU with DS leakage of ammonia was trained in Bučovice. [4]

Other examples of trainings will be given in the following chapter.

The issue of simulation and modeling of leakage of dangerous substances is dealt in the following publications. Björnham Oscar et al.[5] discuss the risks of chemical leakage during transportation in a densely populated area and its impacts. By analysis of fluid dynamics deals Sun et al. [6]. A direct comparison of two selected SWs is given in Ficek et al. [7]. From the point of view of simulation and modeling, Inanloo et al. [8] achieved very interesting results in modeling the combustion vapor explosion.Bernatik et al. [9] dealt with the much needed addition of models of computational fluid dynamics for common SW such as Terex or Aloha or physical modeling in aerodynamic tunnels which provides data that can be compared with the outputs of conventional SW.

This issue is addressed also in scientific circles as can be seen in previous paragraph. Dangerous substances are used in products, processes, and procedures in many facilities and factories. Therefore, these substances must be stored and transported. Usually leaks occur at these stages. These leaks must be solved by forces and means of IRS.In order to better preparation for EEs with leakage of dangerous substances of the FRS and $\mathrm{CM}$ components, trainings, simulations and modeling are carried out. Therefore, the simulation and modeling possibilities, especially the possible developments in SW simulation and modeling for IRS, need to be addressed. In this paper, selected IZS trainings focusing on leakage of dangerous substances will be analyzed by SWOT analysis. This paper will also review current SW tools for simulation and modeling of leakage of dangerous substances. Based on expert consultations with experts, a possible development will be proposed for SW simulation and modeling in crisis management aimed at leakage of dangerous substance.

Evaluation of realized trainings:

February 7, 2017 - Training of the IRS components in the training hockey hall in Trinec, where 7 units of FRS and FPO practiced intervention in case of leakage of ammonia from the cooling device. DS leaked from a pipe in the cooling device in the engine room. This leak was detected by a sensor at a concentration of $300 \mathrm{ppm}$ (this value exceeds the limit for ERPGs 2). In terms of simulating DS spreading, it is essential that the leakage was within 
in the building. The exact amount of leakage and the size of the hole are unknown, but the precise substance is known. For the training, the approximate infiltration sector was predetermined. When we tried to simulate the propagation of the substance using two different SW, different results were achieved. The procedure of the units was highly professional; however, in terms of the simulated leakage of dangerous substance, the distribution of the substance was not fully taken into account. To improve this, we recommend to simulate the propagation of the substance by several SW and based on the result determine the propagation.

6 units of FRS and FPO participated in tactical training on the premises of the company MP Krásno in Ostrava-Martinov aimed at eliminating of the consequences of ammonia leakage from the cooling pipeline in the engine room took place on June 29, 2017. This involved two leaks of liquid ammonia in the building. Even in this case, FRS and FPO units are well prepared and trained and the intervention itself was professional. In terms of simulation, this situation is rather problematic. If a substance is spread in an object, it would be difficult to model two leaks that are intermingled for some time. Determining, for example, the resulting concentration would be problematic. During this training, the technical means, that prevented the propagation of the substance from the leakage site (engine room, compressor), should be used in the simulations to take into account the DS diffusion and interference. It would be useful to use SW with the possibilities of complex simulations that provide a relatively good result of the threat.

In the hockey hall Polárka in Frýdek-Místek took place an training focused on leakage of ammonia. It took place on January 31, 2017 and 7 units of FRS and FPO participated. In this tactical training, ammonia leaked from the cooling device (cracked valve) in the engine room. Leakage was detected by a sensor at a concentration of $50 \mathrm{ppm}$. The intervention was highly professional and efficient. In terms of simulation, it is interesting that the deflectors have been set up outside, so they did not disguise the propagation of substance within the object.It may be advisable to use SW to simulate the spread of DS in the object and thus to work better with this data and to check the procedure to prevent DS from spreading within the building.

At the slaughterhouse in Bučovice, on 3 March 2017, training was conducted in which ammonia leaked after a technical defect on the cooling equipment. There were 5 units of FRS and FPO. The intervention itself was professional and effective. In terms of simulation, the influence of the propagation of DS in the object itself and the subsequent propagation outside the object was simulated. The simulation and modeling options showed how effective can be data obtained during training and how to adjust the upcoming training if we really expect the worst-case scenario.

The 4 trainings mentioned above, which took place in the first half of 2017, were focused on the leakage of dangerous substances (ammonia). Although ammonia is most likely to leak in the Czech Republic, it would be appropriate to train the leakage of other substances in the future; however, the unit progress would be essentially the same or the same. In terms of modeling and simulation, it was found that the IRS does not use SW.The last example demonstrates that the usage of SW to model the propagation of DS in a building can contribute to the improvement of the training. This statement are based on simulations and analyzes (SWOT), but since it is only a training where there are no real leakage data, the author does not consider the analysis to be as significant to be stated in the article.

\section{CONSULTATION WITH EXPERTS AND DEFINITION OF THE TASKS OF THE IRS}

The following information was obtained through personal meetings with IRS experts and Crisis Management staff. Interestingly, the responses were largely coincided, that is why there are only few suggestions and answers.

Experts have defined very simple and generally on:

- Transportation of resources.

- Assessing the situation at the site of intervention.

- Create an intervention base

- Preparation of resources.

- Intervention.

- Finishing of intervention and return.

In the case of a leakage of a dangerous substance, the tasks of the units are to reduce the immediate risks and limit the extent of the accident in order to stabilize the situation:

- exploration (if a dangerous substance accident is involved),

- measures to save people and animals and closure of a intervention site,

- calling assistance, including units specializing in an accident with a dangerous substance,

- ensure a sufficient distance from the intervention site to the wind direction,

- close the intervention site, identify the dangerous and outer zones,

- exclude sources of initiation,

- prepare resources for intervention,

- if it is possible, prevent further leakage or spreading of a dangerous substance,

- identification of a dangerous substance, provide information about its dangers,

- if possible, take measures to capture or remove dangerous substances,

- continuously evaluate the situation,

- determine the possible amount of leaked dangerous substance, 
- determine the size of the affected area,

- identify the status and possibilities of their change,

- identify the possibility of spreading hazardous substances, wind and weather,

- determine the terrain and settlement density,

- identify potential threats to surface or groundwater,

- determine the rate of leakage of the dangerous substance and the rate of its spreading,

- inform residents, relevant institutions and public authorities,

- assess the need for population evacuation or other protection,

- make a prognosis of the further development of the accident with a view to further escalation.

When dividing the intervention site into zones with a distinctive danger, it is at least the creation of:

- dangerous zones,

- outer zones and within them

- the rear area,

- the entrance space,

- decontamination area.

As can be seen from the tasks designed for the intervention with the leakage of DS, it is obvious that SW simulations and modeling for DS leakage have some influence. In the previous task list are underlined those points where it is possible to use this software. Bold are then actions that are necessary to get the basic information needed for the proper function of each simulation and modeling software.

Further, consultations with experts showed that it is necessary to partially improve the user interface for the existing SW, but especially the accuracy of the calculation of the vulnerable area. Furthermore, the proposal for a wider database of substances and a more detailed description of these substances (mainly the possibility of chemical reaction of these substances with other substances). Generally, they would also glad if the SW were created for their needs. Expert requirements will be discussed in more detail in the following two chapters, namely: Evaluation of current SW and Identification of the possible development of SW.

\section{Evaluation of current SW}

The software must be assessed on the basis of their designation, i.e. in relation to the previous chapter, namely: identification of dangerous and outer zones, information on its danger of dangerous substances, continuous assessment of the situation, determination of the size of the affected area, assessment of the necessity of population evacuation or other protection,the prognosis of the further development of the accident with respect to the possibility of further gradation. In addition, it is necessary to take into account the determination of the program whether it is intended for intervention units or for crisis and emergency planning.

\section{These will be the parameters for SW evaluation}

For SW needs: Determination of the approximate amount of leaked dangerous substance, the state of DS, the possibility of spreading dangerous substance - wind direction and weather development, the terrain and population density, the rate of leaked substance and the rate of its spreading.

Because the individual software often operates on similar principles, there will be only given a summary description of only a few selected SW, two of them will then be selected, compared and evaluated.

Specifically, the software:

- Aloha

- Terex

- Effect

- Save II

- Rozex alarm

SAVE II - it is a numerical program focusing on the leakage of substances and their dispersion. It works on the principles of the Gaussian model and methodologies CPR 14 and CPR 18. The program allows modeling and simulating the following: continuous leakage followed by dispersion of toxic substance, leakage followed by dispersion of toxic substance, continuous leakage of the substance followed by explosion, substance leakage followed by explosion, and turbulent leakage.

EFFECTS - the program provides an estimate of possible physical effects of leakage of toxic and flammable substances. It uses Pasquill typing and wind speed; models operate with open smooth terrain, so it is necessary to specify the coefficient of surface roughness. The Gaussian model is used to propagate neutral gas. It is also possible to perform heavy gas modeling in the form of: instantaneous leakage, leakage of gas or dispersion by evaporation from the pool, dispersion resulting from turbulent/nozzle leakage. Gas dispersion in the atmosphere: Neutral gas dispersion model, heavy gas dispersion model, turbulent gas leakage model. Passive dispersion: Immediate leakage (up to 1 minute), semicontinuous leakage (1 to 10 minutes), continuous leakage (longer than 10 minutes).

ROZEX Alarm - the program provides leakage modeling of hazardous chemicals. The program database includes 10,000 DS with additional information. It works with up to 19 variants of scenarios. Again, the principle of maximum possible damage is applied. The program is designed to require minimum input data. For modeling atmospheric dispersion, the program offers the following basic options:

- leakage of toxic substances - for neutral gas and heavy gas,

- continuous leakage of toxic substances - for neutral gas and heavy gas, 
- continuous leakage of toxic substances through the opening - for neutral gas and heavy gas.

ALOHA - Areal Locations of Hazardous Atmospheres operates with statistical mathematical models (SLAB and DEGEADIS). The software shows the maximum concentration of $\mathrm{NL}$ and its range. It provides three basic options: cloud leakage, instantaneous leakage and "accidental" leakage.

Advantages: large database of substances, it is possible to connect SW with measuring devices.

Disadvantage: works only with nonreactive substances.

It works with the following input data:

- Leakage data

- Data on the state of the atmosphere

- Data leakage source

Output data:

- The maximum leak rate - for liquids, it is the rate of evaporation, not the leakage rate.

- The average leak rate for at least 1 minute; for liquids, it is the rate of evaporation. For pressurized devices, a sudden initial leakage may result in overestimation.

- Total leakage of substance over a maximum of 1 hour.

- The maximum range of the hazardous zone in which the concentration reaches the specified value.

- Maximum concentration of leaked substance at any given location.

- The maximum dose at the selected site, which was absorbed by the body within 1 hour.

TEREX - works with chemicals and explosive systems. The program is based on the conservative prognosis principle. The program needs relatively few input data: the amount of leakage, the wind speed, the air temperature, the type of environment, the cloudiness, and the time of occurrence. For each substance, additional information can be found. This software works with the following models: TOXI - evaluates the range and shape of the cloud, PLUME - this is a long-lasting leakage of gas into the cloud, a long-lasting leakage of boiling liquid with rapid evaporation into the cloud, slow evaporation of the liquid from the puddle to the cloud. PUFF - gas leakage into the cloud, rapid flow of boiling liquid into the cloud. TEROR - use of explosives. VCE, UVCE - leakage by explosion of a dangerous substance, such as: evaluation of the impact waves caused by the detonation of the mixture of substance with air. POOL FIRE, JET FIRE, FLASH FIRE and BLEVE - escape of combustible dangerous substance, these models evaluate the range of thermal radiation of fires.

- Advantage: Simple setup.

- Disadvantage: insufficient amount of chemicals in database.

\section{EVALUATION USING SWOT ANALYSIS}

In order to obtain the data for the assessment, we compare actual situations and their threat zones (ERPG-3) with the results of simulations and models in SW Terex and Aloha. Although systems operate with different mathematical models, they can be compared in this way, because the systems use input data as variables, and mathematical equations themselves are predefined.

The student's t-test is used for statistical evaluation.

Then, the statistics are applied to data from the table (real and ALOHA or TEREX), from which the hypothesis decision $\mathrm{H}_{0}$ is determined. $\mathrm{H}_{0}$ is the hypothesis that the mean values are equal.

According to the procedure, we find that the arithmetic mean of the difference between the measured reach of the substance and the simulated range in SW Aloha is -2.7989 , the number of measurements is 10 and the variance $s^{2}$ is 2.397465071 .

\begin{tabular}{|c|c|c|c|c|c|}
\hline Situation & Substance & Amount $[\mathrm{kg}]$ & Real $[\mathrm{km}]$ & ALOHA $[\mathrm{km}]$ & TEREX $[\mathrm{km}]$ \\
\hline 1 & chlorine & 188 & 0.431 & 7.2 & 0.462 \\
\hline 2 & ammonia & 90 & 0.25 & 2.85 & 0.15 \\
\hline 3 & hydrogen chloride & 55 & 0.56 & 0.49 & 0.57 \\
\hline 4 & methyl chloride & 124 & 0.16 & 0.78 & 0.166 \\
\hline 5 & acetaldehyde & 79 & 0.18 & 1.3 & 0.201 \\
\hline 6 & benzene & 134 & 0.27 & 0.86 & 0.291 \\
\hline 7 & hydrogen fluoride & 70 & 0.76 & 3.81 & 0.7 \\
\hline 8 & ammonia & 50 & 0.17 & 2.8 & 0.194 \\
\hline 9 & formaldehyde & 66 & 0.82 & 5.1 & 0.836 \\
\hline 10 & chlorine & 89 & 1.3 & 7.7 & 1.319 \\
\hline
\end{tabular}


Once these values have been matched to the equation

$$
t=\frac{|X|}{\sqrt{\frac{s^{2}}{n}}}
$$

The result is $t=5.71625$.

Tabulated critical value $t_{1}-\alpha / 2(v)$, where $v=n-1$ and $\alpha$ is chosen to 0.05 , is 0.05 , the conclusion therefore is that: $t>t_{1}-\alpha / 2(v)$. So there is a statistically significant difference.

We reject the zero hypotheses $\mathrm{H}_{0}$, i.e. the mean value of the measured values differs from the mean value of the simulated values using SW Aloha.
Applying the same procedure for SW Terex results in: Calculated value $t=0.021353$

The tabulated critical value $t_{1}-\alpha / 2(v)$, where $v=n-1$ and $\alpha$ is 0.05 , is equal to 3.25 .

Thus: $\mathrm{t}<\mathrm{t}_{1}-\mathrm{\alpha} / 2(\mathrm{v})$.

So there is a statistically insignificant difference. We accept the zero hypotheses $\mathrm{H}_{0}$, i.e. the mean value of the real values is not significantly different from the mean value of the simulated values using SW Terex.

Table 1: SWOT analysis Aloha

\begin{tabular}{|l|l|l|}
\hline SWOT - Aloha & Auxiliary & Noxious \\
\hline Inner origin & $\begin{array}{l}\text { Strengths: } \\
\text { The system provides significant simulation capabilities. } \\
\begin{array}{l}\text { Possibility to extend DS through an external database. } \\
\text { Possibility of connection with external measuring stations. }\end{array}\end{array}$ & $\begin{array}{l}\text { Weaknesses: } \\
\text { The results can be distorted. }\end{array}$ \\
\hline External origin & $\begin{array}{l}\text { Opportunities: } \\
\text { Work with 3D terrain models. } \\
\text { Terrain optimization. } \\
\text { Improvement of numerical models. }\end{array}$ & $\begin{array}{l}\text { Threats: } \\
\text { As a result of oversize results, re- } \\
\text { sults will not be taken into account. }\end{array}$ \\
\hline
\end{tabular}

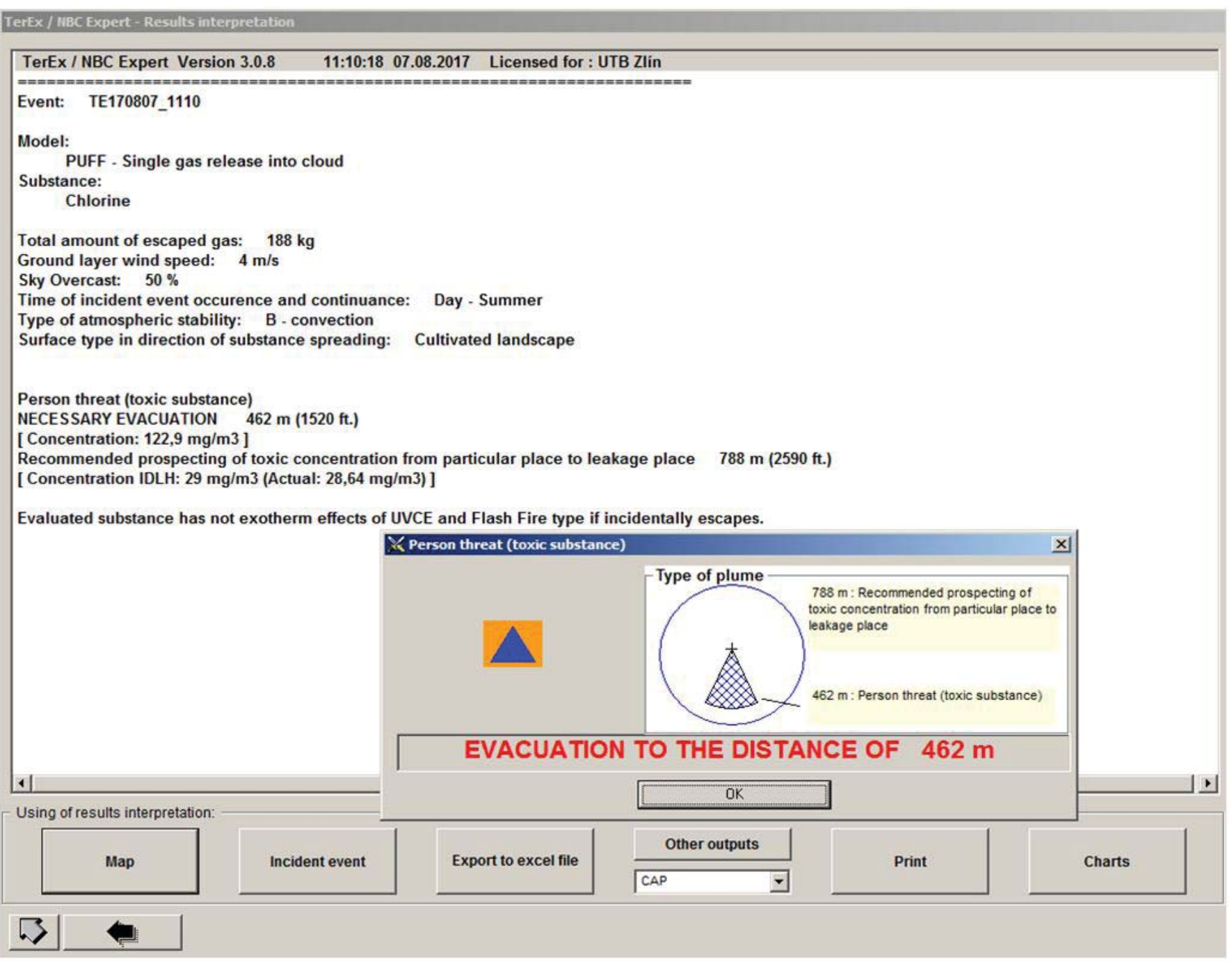




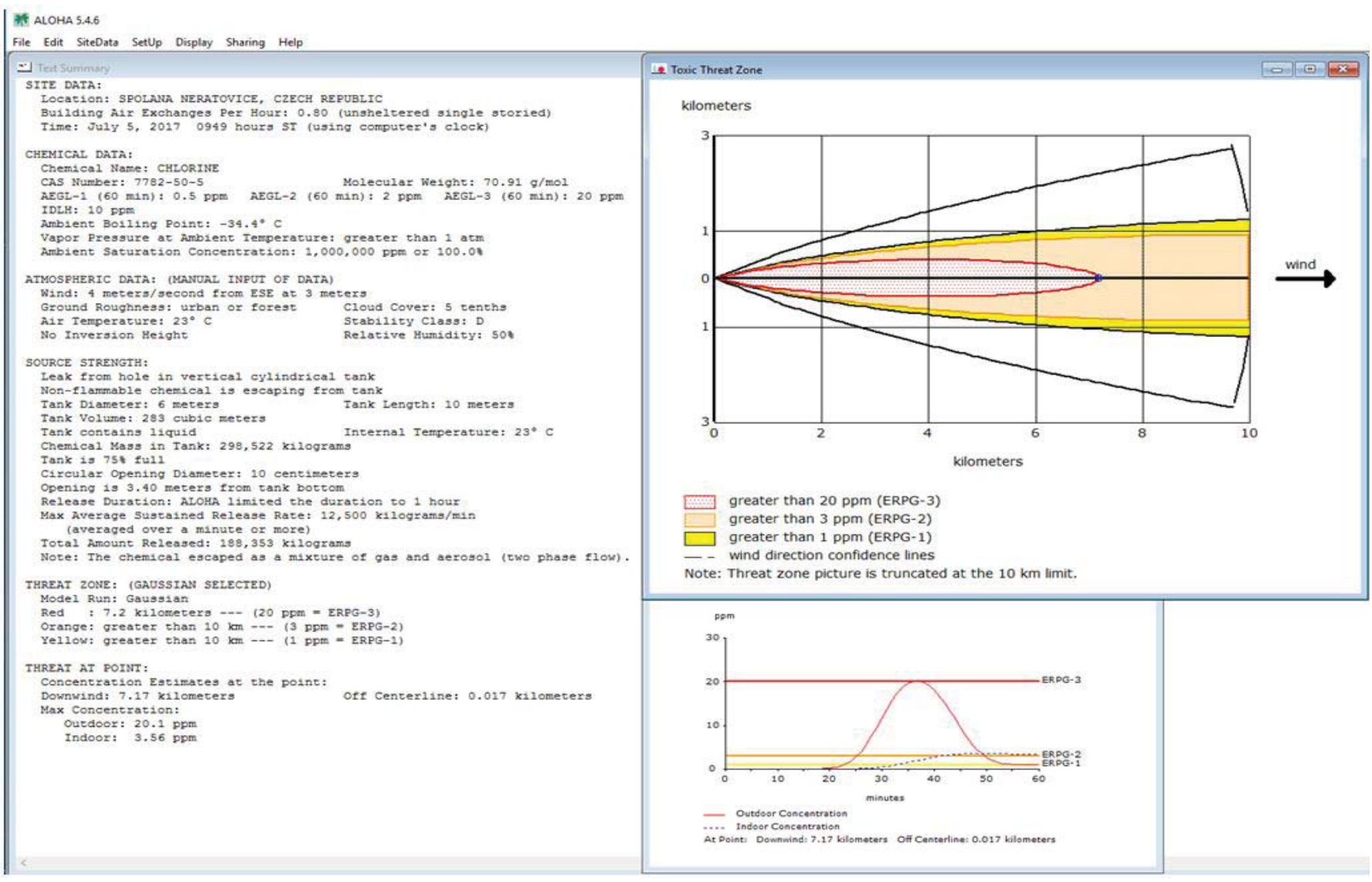

The quantification of this SWOT analysis is as follows:

\begin{tabular}{|c|c|c|c|}
\hline$\underline{\text { Strengths }}$ & $\underline{\text { Rating }}$ & Weight & $\underline{\text { Result }}$ \\
\hline The system provides significant simulation capabilities & 5 & 0.4 & 2 \\
\hline Possibility to extend DS through an external database & 4 & 0.2 & 0.8 \\
\hline Possibility of connection with external measuring stations & 5 & 0.4 & 2 \\
\hline Total & & & 4.8 \\
\hline Weaknesses & Rating & Weight & Result \\
\hline The results can be distorted & -4.5 & 1 & -4.5 \\
\hline Total & & & -4.5 \\
\hline Opportunities & Rating & $\underline{\text { Weight }}$ & $\underline{\text { Result }}$ \\
\hline Work with 3D terrain models & 4.5 & 0.3 & 1.35 \\
\hline Terrain optimization & 4 & 0.2 & 0.8 \\
\hline Improvement of numerical models & 5 & 0.5 & 2.5 \\
\hline Total & & & 4.15 \\
\hline$\underline{\text { Threats }}$ & $\underline{\text { Rating }}$ & Weight & $\underline{\text { Result }}$ \\
\hline $\begin{array}{l}\text { As a result of oversize results, results will not be taken into } \\
\text { account }\end{array}$ & -4 & 1 & -4 \\
\hline Total & & & -4 \\
\hline
\end{tabular}


Internal Value $=$ Strengths + Weaknesses $=4.8-4.5=0.3$ External Value $=$ Opportunities + Threats $=4.15-4=0.15$ Result value $=$ Internal value + External value $=0.3+$ $0.15=0.45$

SW Aloha has a relatively low result, due to overrated results, which are not suitable for use in $\mathrm{CR}$. It is true that the principle of protection of the population is: "expect the worst, at least you will be prepared", but SW Aloha is overrating the results so much that any intervention, according to the results, would be much more expensive and would lack in efficiency. However, SW Aloha is well-suited for crisis planning as it allows complex simulations to provide important information. Therefore, it should not be neglected.

The following section will focus on possible developments in the field of SW simulation and modeling of leakage of dangerous substances.

\section{IDENTIFICATION OF POSSIBLE SW DEVELOPMENT}

Generally, it is necessary to deal with the possible developments in SW simulation and modeling. This is about refining models for calculating threat zones. This trend is valid for all SWs. Other trends are for certain groups of these SW. These trends include: involvement of 3D terrain models and air layers, simplifying the interface for enrolling and creating simulations, optimizing SW for field use, and for another group of optimizations, in order to create more complex simulations, and it would be appropriate for all SWs to be connected with other devices such as measuring and monitoring stations.

Expert consultations have led to the desire for SW to work primarily on devices (workstations, smartphones. etc), but would also communicate on a client-server basis, ensuring constant up-to-date information thusensuring functionality during server malfunction.Also, the ability to share results with other users could contribute to more effective interventions.

It is understandable that each SW will have specific properties and therefore specific possibilities for further development, but the goal is to identify possible developments in simulation and modeling software for leakage of dangerous substance.

\section{CONCLUSION}

Leakage of dangerous substances is an extraordinary situation that is threatening almost every day. This is mainly due to the dependence of today's society on these substances. It is always necessary to transport and use DS in a variety of facilities and technological processes. Therefore, there is a need to plan for the situations of DS leakage. To plan for such situations, you need to know the threat zones. This is useful for SW, that models and simulates the leakage of DS and calculate the threat zone. From time to time there is a leak of DS, in this case the use of simulation and modeling software to determine the threat zone.

Two SW were selected in the article, namely SW Aloha and SW Terex. Real situations were entered into these SWs and the results were compared with real measured data. The evaluation was carried out on two levels, in the form of a statistical part. In this section it was found that SW Aloha has statistically significant differences in the threat zones compared to the real situation. SW Terex has statistically insignificant differences in the same comparison.

The second comparison was done through SWOT analysis. It is focused on the entire SW. For each SW, the results differed, and generally the selected SW can be evaluated as relatively effective, but each has its primary purpose. SW Aloha is better to use in crisis planning, where there is plenty of time and allows more complex simulations. While SW Terex is more likely to be used during interventions, due to its relative accuracy and simplicity.

In the near future, possible developments should be in 3D modeling of terrain and air layers. Furthermore, creating an interface,that would simplify the creation of simulation during intervention, and at the same time enable comprehensive and complex simulation to be used for crisis planning.And finally, the possibility of connecting SWs and sensors or actors will be developed. The SW function is based on the hybrid principle client-server and SW on workstations.

It may seem that this area has already been explored, but the refinement of the models and the results of the simulations combined with the connection with sensors and actor models can make a significant contribution to a safer future.

\section{ACKNOWLEDGEMENT}

This work was supported by the Internal Grant Agency of Tomas Bata University under the project No. IGA/ $\mathrm{FAl} / 2018 / 014$

\section{REFERENCES}

1. Hzs moravskoslezského kraje.První cvičení složek IZS v tréninkové hokejové hale v Třinci, fromhttp:// www.hzscr.cz/clanek/prvni-cviceni-slozek-izs-vtreninkove-hokejove-hale-v-trinci.aspx, accessed on2017-09-25.

2. Hzsmoravskoslezskeho kraje.Cvičení s únikem amoniaku $v$ areálu $v$ Ostravě-Martinově, fromhttp://www.hzscr.cz/clanek/cviceni-s-unikem-amoniaku-v-arealu-v-ostrave-martinove.aspx,accessed on2017-09-25.

3. Hzsmoravskoslezskeho kraje.V hokejové hale Polárka ve Frýdku-Místku unikal amoniak a zranil obsluhu, fromhttp://www.hzscr.cz/clanek/v-hokejove-hale-polarka-ve-frydku-mistku-unikal-amoniaka-zranil-obsluhu.aspx, accessed on2017-09-25. 
4. Požáry.cz.Hasiči nacvičovali zásah při úniku čpavku v Bučovicích na Vyškovsku, fromhttps://www.pozary. cz/clanek/158139-hasici-nacvicovali-zasah-pri-uniku-cpavku-v-bucovicich-na-vyskovsku,accessed on2017-09-25.

5. Björnham O., Burman J., Parmhed O., Fureby C. 2014Crisis Management Modeling and SimulationLaboratory. In: Steyn D., Builtjes P., Timmermans R. (eds) Air Pollution Modeling and itsApplication XXII. NATO Science forPeace and SecuritySeries C: EnvironmentalSecurity. Springer, Dordrecht

6. SUN, H., NING, P., TANG, L. 2010. ApplicationofComputational Fluid Dynamics forManufacturedGasDispersion Modeling and LeakageConsequenceAnalysis. In: 7th International Symposium on
Safety Science and Technology (ISSST). Hangzhou, PEOPLES R CHINA. ISBN 978-7-03-029089-2.

7. FICEK, M., VIČAR, D., RAK, J., SVOBODA, P. 2016Usingthe SW modeling and simulatingtools in transport ofhazardouscargos. In: TRANSPORT MEANS 2016. Juodkrante, Lithuania: Kaunas university of technology, p. 862-865. ISSN 2351-7034.

8. INANLOO, B.et al., 2015. Explosionimpalsduring transport ofhazardouscargo: GIS-basedcharacterizationofoverpressureimpacts and delineationofflammablezonesforammonia. In: JournalofEnvironmental Management. s. 1-9. DOI: 10.1016/j.jenvman.2015.02.044. ISSN 03014797.

9. BERNATIK, A. et al., 2008. Modelling accidentalreleasesofdangerousGatesintotheLoirtropospherefrom mobile sources. In: ProcessSafety and EnvironmentalProtection. p. 198-207. DOI: 10.1016/j. psep.2007.12.002. ISSN 09575820. 